\title{
Synthesis and Biosynthetic Trafficking of Membrane Lipids
}

\author{
Tomas Blom ${ }^{1}$, Pentti Somerharjü ${ }^{2}$, and Elina Ikonen ${ }^{1}$ \\ ${ }^{1}$ Institute of Biomedicine, Department of Anatomy, University of Helsinki, FIN-00014 Finland \\ ${ }^{2}$ Institute of Biomedicine, Department of Medical Biochemistry and Developmental Biology, University \\ of Helsinki, FIN-00014 Finland \\ Correspondence: tomas.blom@helsinki.fi
}

Eukaryotic cells can synthesize thousands of different lipid molecules that are incorporated into their membranes. This involves the activity of hundreds of enzymes with the task of creating lipid diversity. In addition, there are several, typically redundant, mechanisms to transport lipids from their site of synthesis to other cellular membranes. Biosynthetic lipid transport helps to ensure that each cellular compartment will have its characteristic lipid composition that supports the functions of the associated proteins. In this article, we provide an overview of the biosynthesis of the major lipid constituents of cell membranes, that is, glycerophospholipids, sphingolipids, and sterols, and discuss the mechanisms by which these newly synthesized lipids are delivered to their target membranes.

$T_{\text {sit }}^{\text {he }}$ he endoplasmic reticulum (ER) is the main site for lipid synthesis. Intracellular lipid trafficking is necessary to maintain most other organelle membranes as they lack the capability to synthesize lipids de novo (van Meer et al. 2008). In their target locations, lipids may be present as structural compounds or they may undergo further biosynthetic modifications to generate different lipid species, some of which may be transported further to new destinations. Because of their hydrophobic nature, most lipids cannot be effectively transferred by free diffusion from one compartment to another and must therefore rely on active mechanisms to facilitate intercompartmental transport. In principle, three basic mechanisms can be depicted. A major form of trafficking is membrane transport that involves the budding of vesicles or tubules from a donor membrane and subsequent fusion with an acceptor membrane (Fig. 1A). The acceptor membrane may contain enzymes that modify the inserted lipids, helping to generate a lipid composition that differs from the donor membrane. In addition, cells use cytosolic carrier proteins for transferring lipids between compartments (Fig. 1B). The hydrophobic lipid binding pockets of these proteins are selective, allowing only one-or more often, a few closely related-lipid species to bind. Carrier proteins may also contain peptide determinants that target to the donor and acceptor membranes, providing compartmental specificity for transfer. Yet another possibility is the bringing of donor and acceptor

Editor: Kai Simons

Additional Perspectives on The Biology of Lipids available at www.cshperspectives.org

Copyright (C) 2011 Cold Spring Harbor Laboratory Press; all rights reserved; doi: 10.1101/cshperspect.a004713

Cite this article as Cold Spring Harb Perspect Biol 2011;3:a004713 
T. Blom et al.

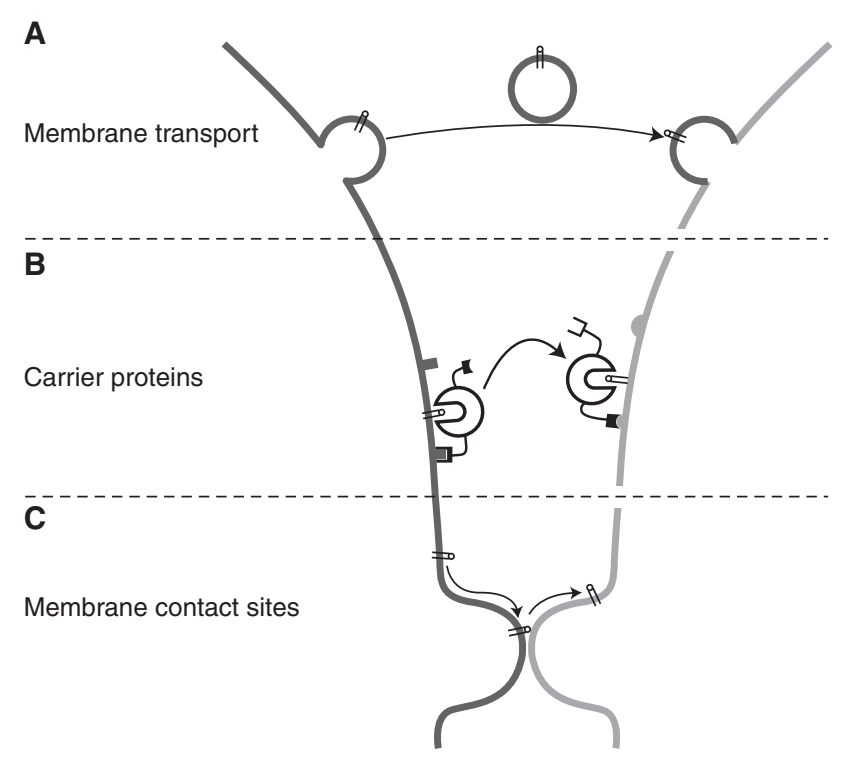

Figure 1. Mechanisms of intermembrane lipid transport. (A) Membrane transport moves lipids together with proteins in vesicular and tubular carriers that bud off from a donor membrane, and are transported along cytoskeletal tracks to the acceptor membrane, in which they fuse to deliver their cargo. (B) Cytosolic carrier proteins transfer lipids in hydrophobic pockets that show selectivity toward one or a few lipid types. Carrier proteins often contain domains that bind to the donor and/or acceptor membranes. $(C)$ Lipid exchange may also occur between membranes that are in very close proximity. Transfer via such membrane contact sites may be facilitated by carrier proteins (combination of models B and C).

membranes into close proximity and transfer of lipids via membrane contact sites (Fig. 1C). In vivo, combinations of these three mechanisms are likely to operate in parallel, but their dissection is not simple.

It was postulated already in the late 1960s that lipid exchange can be facilitated by intracellular lipid transfer proteins (Wirtz and Zilversmit 1969). Following the initial observations, several proteins with lipid transfer activity have been identified and cloned. Based on their lipid binding specificity they are broadly divided into three classes, namely glycerophospholipid, sphingolipid, and sterol transfer proteins (Lev 2010). Proteins that accelerate the exchange of lipids between donor and acceptor membranes in vitro have traditionally been regarded as lipid transfer proteins. However, the in vitro lipid transfer may be a consequence of a general binding activity of a lipid sensing or chaperone domain of the protein, and is not necessarily indicative of a direct physiological role in lipid transfer. Consequently, a long-standing problem has been the unequivocal identification of proteins that are physiologically relevant mediators of intermembrane lipid transfer. Most of the proteins with lipid transfer activity in vitro have been shown to affect lipid metabolism in vivo but apart from a few exceptions, it is at present unknown whether these effects are because of actual lipid transfer activity (Wirtz et al. 2006, D’Angelo et al. 2008).

In addition to targeting lipids to specific cellular compartments, the cell upholds a differential composition of lipids over the membrane bilayer leaflets. The ER membrane leaflets are, however, considered similar in lipid composition because of a high degree of lipid "flipflopping" between leaflets (Kol et al. 2004; Holthuis and Levine 2005). Because of this, the decision whether a lipid will have its head group oriented toward the cytosol or the extracellular environment is largely made in post-ER membranes. Here, cells actively transport lipids to enrich specific lipid types in the cytosolic leaflet, and others in the exoplasmic leaflet. 
The compartmentalization of lipids is involved in regulating cellular functions. For instance, in polarized cells membrane proteins are differentially transported to the apical versus basal plasma membrane. This protein targeting is partially dependent on lipid sorting in the Golgi complex (Simons and Ikonen 1997; Weisz and Rodriguez-Boulan 2009). Similarly, localized sphingolipid metabolism is associated with membrane budding and the formation of exosomes in multivesicular bodies (Trajkovic et al. 2008). Lipids do not only modulate the localization and function of constitutively membrane associated proteins but may also recruit soluble proteins to membranes, by serving as temporally and spatially regulated tags for lipid binding cytosolic proteins.

\section{BIOSYNTHETIC TRAFFICKING OF GLYCEROPHOSPHOLIPIDS}

Glycerophospholipids represent the most abundant class of lipids in mammalian cells. The synthesis of glycerophospholipids takes place in the ER and is initiated by acylation of glycerol 3-phosphate (or acylation and subsequent reduction of dihydroxyacetone-phosphate) to form phosphatidic acid (Fig. 2), from which all other glycerophospholipids are formed by the addition of a polar head group. The most common head group in mammalian cells is choline and the respective phospholipid class, phosphatidylcholines, makes up approximately half of the total cellular phospholipids. Phosphatidylethanolamines, -serines and -inositols are other common mammalian glycerophospholipid classes. Each of them consists of tens or hundreds of different molecular species varying in their alkyl chain composition (van Meer et al. 2008). Accordingly, a single cell may contain thousands of different phospholipid molecules. The functional significance of this complexity is only starting to be unraveled.

\section{Phosphatidylcholine}

Phosphatidylcholine (PC) is formed by the transfer of a phosphocholine group from CDP-choline to a diacylglycerol molecule.
This reaction can take place both in the ER and the Golgi apparatus. In the ER, the final step of PC synthesis is mediated by a choline/ ethanolamine phosphotransferase of dual specificity, whereas a choline specific phosphotransferase catalyzes this reaction in the Golgi (Henneberry and McMaster 1999; Henneberry et al. 2000, 2002). In the ER, PC and other lipids move readily over the bilayer, but in the Golgi, such movement is more restricted (Buton et al. 1996; van Meer et al. 2008). Because PC is the major lipid in most organelle membranes, it must be carried by membrane transport. However, as PC is efficiently transferred from the ER to the plasma membrane when protein secretion is inhibited, nonvesicular mechanisms also play an important role in this transfer (Fig. 5) (Kaplan and Simoni 1985). There are several possible mechanisms of nonvesicular transport of (phospho)lipids, including spontaneous or protein-mediated diffusion and membrane contact-site dependent translocation (Fig. 1), but the relative contributions of these are not known (Voelker 2009). Potentially important phospholipid transfer proteins include StARD2, StARD7, and StARD10, which can bind a PC molecule in a hydrophobic pocket of their steroidogenic acute regulatory protein related lipid transfer (START) domain and mediate intermembrane transfer of $\mathrm{PC}$ in vitro. StARD2 and StARD7 bind PC only, whereas StARD10 binds phosphatidylethanolamine (PE) as well (Olayioye et al. 2005; Wirtz 2006; Kanno et al. 2007; Horibata and Sugimoto 2010; Kang et al. 2010). However, it is unclear if these proteins play a relevant role in phospholipid trafficking in vivo.

\section{Phosphatidylethanolamine}

Phosphatidylethanolamine (PE) is the second most abundant phospholipid in mammalian cells. PE is synthesized either by transfer of phosphoethanolamine from CDP-ethanolamine to diacylglycerol or by decarboxylation of phosphatidylserine (PS) (Vance 2008). The former pathway takes place in the ER and the nuclear envelope and is catalyzed either by ethanolamine phosphotransferase or choline/ethanolamine 
T. Blom et al.
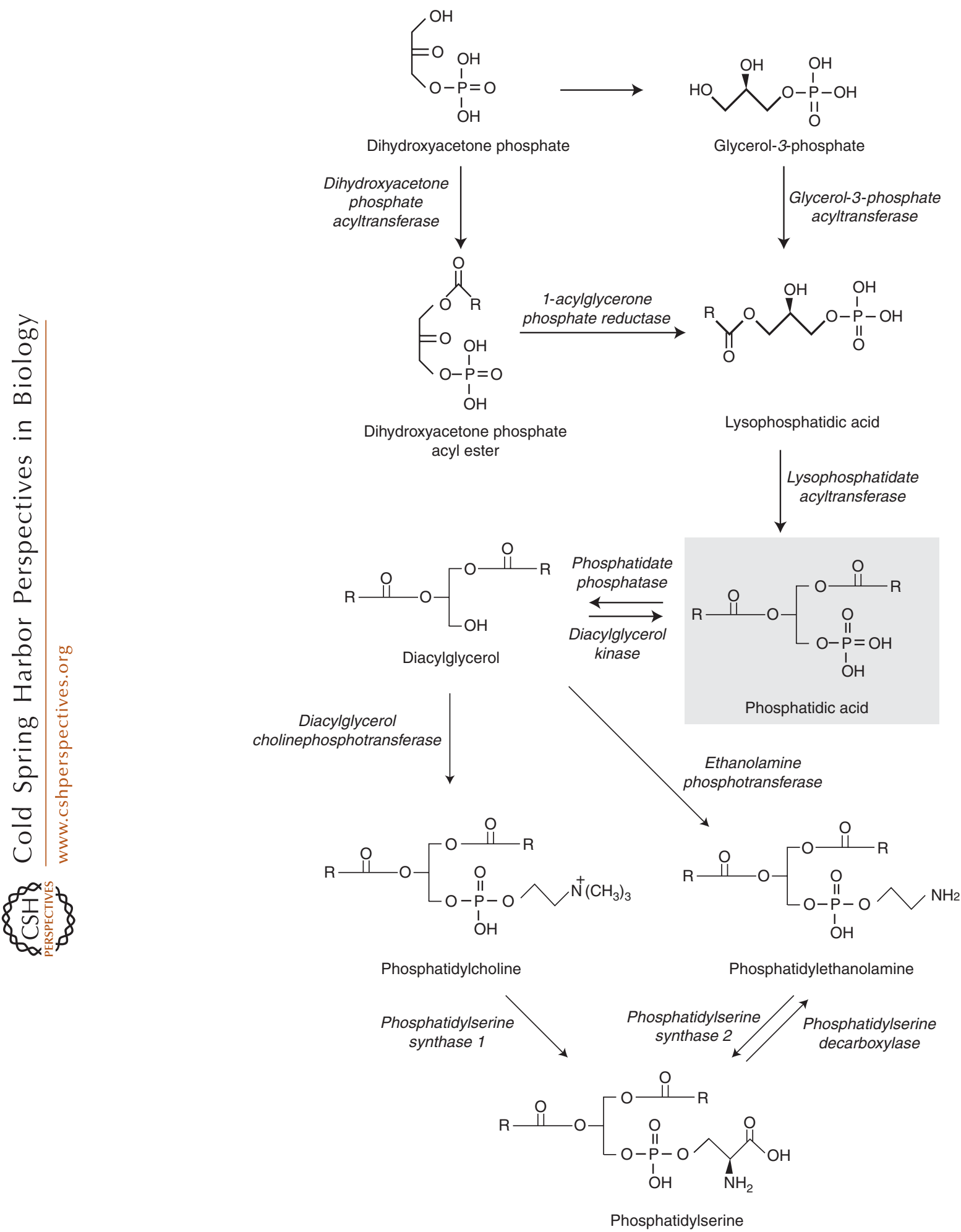

Figure 2. See facing page for legend. 
phosphotransferase (Henneberry and McMaster 1999; Henneberry et al. 2002; Horibata and Hirabayashi 2007). The decarboxylation reaction, on the other hand, takes place in the inner mitochondrial membrane and much, if not all, of the mitochondrial PE derives from this reaction (Zborowski et al. 1983; Shiao et al. 1995; Vance 2008). Elimination of the PS decarboxylase in mice is lethal, probably because (1) PE is essential for the proper structure and function of mitochondria and (2) the PE formed in the endoplasmic reticulum via the CDP-ethanolamine pathway cannot be efficiently imported into mitochondria (Steenbergen et al. 2005). Notably, not all of the PE formed by decarboxylation of PS remains in mitochondria, but is transported to the ER and other organelles. The mechanism(s) of PE transport out of mitochondria remain to be established, but could be similar to that of PS transport from the ER to mitochondria (Achleitner et al. 1995, 1999) (see below). In the plasma membrane, most of the PE is found in the inner leaflet and this asymmetrical distribution is maintained by P-type ATPases (Riekhof and Voelker 2009).

\section{Phosphatidylserine}

In mammalian cells, PS is synthesized by exchanging the polar head group of a PC or a PE molecule for serine. The PS synthases 1 and 2 responsible for this reaction are highly enriched in mitochondria-associated ER domains (Fig. 5) (Stone and Vance 2000). From there, phosphatidylserine translocates to other organelles, such as the plasma membrane as well as to mitochondria where it is decarboxylated to PE. In the plasma membrane, PS is abundant but resides almost exclusively in the cytoplasmic leaflet. Such asymmetrical distribution of PS is maintained by an ATP-driven PS translocation (catalyzed by a yet unidentified protein) from the outer to the inner leaflet (Daleke 2007; Smriti et al. 2007). PS interacts with and regulates several important enzymes, including protein kinase $\mathrm{C}$ in the cytoplasmic leaflet of the plasma membrane (Nishizuka 1992). In addition, loss of the transbilayer asymmetry of PS is one of the hallmarks of apoptosis (Leventis and Grinstein 2010).

Interestingly, the transport of PS from the ER to mitochondria is a relatively slow process with a half-time of several hours (Voelker 1985; Heikinheimo and Somerharju 1998). The mechanism of this transfer process has not been resolved. It has been proposed that the close apposition of mitochondria and the ER membranes is important for the transfer, and the transfer may be mediated by specific proteins located at the ER/mitochondria contact sites (Vance 2008). However, the relatively slow transfer of PS in general as well as faster transfer of the less hydrophobic PS species from ER to mitochondria implies that spontaneous diffusion of PS monomers via the cytoplasm may also contribute to this process (Heikinheimo and Somerharju 2002). PS may move by lateral diffusion via membrane contact sites from the outer to the inner mitochondrial membrane where PS decarboxylase resides (Jasinska et al. 1993).

\section{BIOSYNTHETIC SPHINGOLIPID TRAFFICKING}

Numerous types of sphingolipid species exist in eukaryotic cells and most of them are enriched in the plasma membrane. Sphingomyelin (SM) and glycosphingolipids (GSLs) are important structural lipids that, together with cholesterol,

Figure 2. An overview of the biosynthetic pathways of major glycerophospholipids. De novo synthesis of the glycerophospholipids begins in the ER by a series of reduction and acylation reactions leading to the formation of phosphatidic acid. Dephosphorylation of phosphatidic acid yields diacylglycerol, which can be turned into phosphatidylcholine or phosphatidylethanolamine by the addition of a phosphocholine or a phosphoethanolamine head group, respectively. Phosphatidylserine is formed by exchanging the head group from either phosphatidylcholine or phosphatidylethanolamine for serine. Mitochondrial phosphatidylethanolamine is synthesized on location by decarboxylation of phosphatidylserine. 
T. Blom et al.

are thought to participate in the formation of membrane domains which can affect the distribution and function of membrane proteins (Coskun and Simons 2010). On the other hand, some less abundant sphingolipids, such as sphingosine, sphingosine-1-phosphate, and ceramide, are important modulators of cell signaling (Hannun and Obeid 2008). The enzymes that catalyze the different steps in the synthesis of the more complex sphingolipids (e.g., SM and GSLs) differ in their subcellular location and membrane sidedness. Thus, the synthesis of complex sphingolipids requires both interorganelle and transbilayer lipid movement.

The initial steps of sphingolipid synthesis take place on the cytosolic face of the ER (Fig. 3). First, 3-dehydrosphinganine is formed by condensation of serine and palmitoyl-CoA by the enzyme serine palmitoyl transferase (SPT). The 3-dehydrosphinganine is then reduced to sphinganine by 3-dehydrosphinganine reductase (Futerman and Riezman 2005; Sabourdy et al. 2008). Sphinganine can be $\mathrm{N}$-acylated by one of the several ceramide synthases to form dihydroceramide (Lahiri and Futerman 2007) with an acyl chain of varying length and degree of unsaturation. This provides diversity in the membrane behavior of the sphingolipids eventually formed (Ewers et al. 2010; Koivusalo et al. 2007). Dihydroceramide is then converted to ceramide by a desaturase residing in the ER. Ceramide is the first lipid in the de novo synthesis pathway that contains a sphingosine backbone, and can therefore be considered a central compound in sphingolipid metabolism.

Ceramide can be further metabolized to other sphingolipids by the addition of a polar head group or by removal or exchange of the acyl chain in the recycling pathway. Most of the newly synthesized ceramide is used in the Golgi for the synthesis of SM and glycosphingolipids (Tafesse et al. 2006). In oligodendrocytes ceramide can be glycosylated in the ER to form galactosylceramide which is an important constituent of the myelin sheath (Raff et al. 1978; Stoffel and Bosio 1997; Sprong et al. 2003). In mammalian cells, the sphingoid backbone is almost invariably composed of 18 carbon units $\left(\mathrm{C}_{18}\right)$. Diversity - and alterations in the membrane behavior of the sphingolipid-is achieved by linking acyl chains with varying length and degree of saturation to the sphingosine backbone. In addition to its impact on membrane fluidity, the variations in the acyl chain moiety has functional implications, such as affecting, for example, endocytosis of virus particles (Ewers et al. 2010) and the organization of myelin sheaths (Ben-David and Futerman 2010).

\section{Sphingomyelin}

The synthesis of SM, the major sphingolipid in the plasma membrane, takes place in the Golgi and requires transfer of the ceramide precursor from the ER. Ceramide can be transferred from the ER either in transport vesicles or by soluble transfer proteins. In mammalian cells the latter route dominates and is mediated by the ceramide transport protein (CERT) that takes ceramide from the cytosolic leaflet of the ER and transfers it to the trans-Golgi cisternae where it is converted to $\mathrm{SM}$ by sphingomyelin synthase 1 (SMS1) (Hanada et al. 2003, 2009; Yamaji et al. 2008). CERT is a cytosolic protein with four domains that are needed for transfer of ceramide from the ER to the Golgi. The aminoterminal pleckstrin homology $(\mathrm{PH})$ domain specifically binds to phosphatidyl inositol-4phosphate, a phospholipid that is abundant in Golgi membranes. The PH domain is crucial for targeting of CERT to the Golgi apparatus, because mutations in the $\mathrm{PH}$ domain can impair binding of CERT to the Golgi, thus inhibiting the synthesis of SM (Hanada et al. 2003). The START domain in the carboxyl terminus of CERT is responsible for extracting ceramide from the cytosolic leaflet of the ER. The START domain of CERT has a high specificity for ceramide as it does not transfer other sphingolipids or cholesterol in vitro (Kumagai et al. 2005). Molecular modeling studies have shown that the START domain binds one ceramide in its hydrophobic pocket, suggesting that CERT carries a single ceramide at a time from the ER to the Golgi (Kudo et al. 2008, 2010). CERT also contains a FFAT motif that mediates binding to the ER-resident protein 

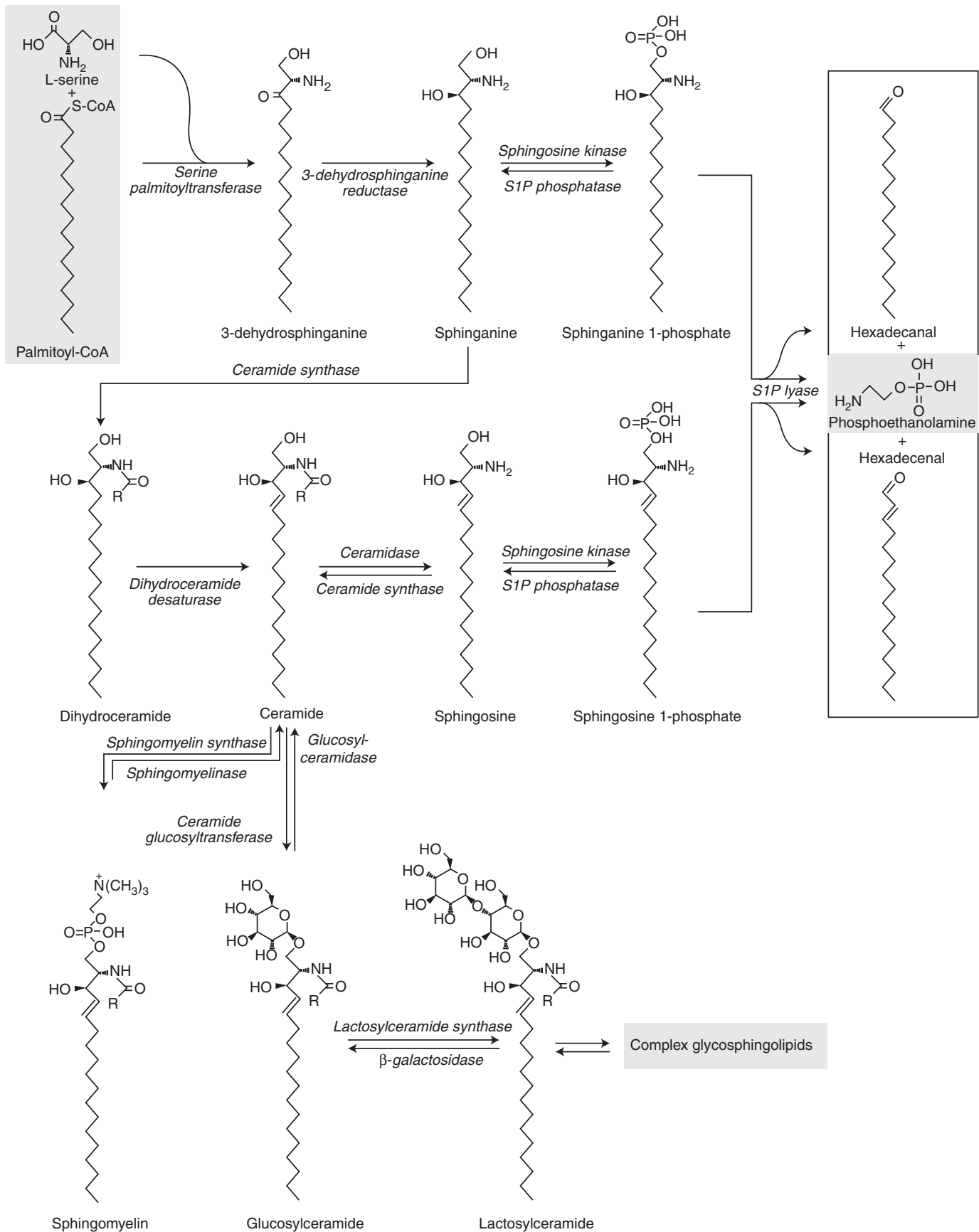

Figure 3. Overview of the biosynthetic pathways of sphingolipids. The sphingoid backbone is formed by the condensation of serine and palmitoyl-CoA. Three further synthetic steps are needed to produce ceramide, which the first compound with a bona fide sphingosine backbone. After its synthesis in the ER, ceramide can be metabolized into sphingomyelin or glycosphingolipids in the lumenal leaflet of the Golgi. The postceramide metabolic steps are reversible and ceramide can also be formed by the sequential degradation of more complex sphingolipids. Deacylation of ceramide yields sphingosine that can be phosphorylated to sphingosine-1-phosphate. The irreversible degradation of the sphingoid backbone is catalyzed by a lyase that acts on either sphingosine-1phosphate or sphinganine-1-phosphate. 
T. Blom et al.

VAP and thus allows CERT to target to the ER. Next to the $\mathrm{PH}$ domain there is a serine repeat motif that regulates the activity of CERT. Hyperphosphorylation of the serines in this motif impairs binding of CERT to the ER and Golgi membranes, thus inhibiting ceramide transfer from the ER to the Golgi (Yamaji et al. 2008; Hanada et al. 2009; Voelker 2009).

\section{Glycosphingolipids}

The synthesis of glycosphingolipids from ceramide takes place mainly in the Golgi apparatus. Similarly to SM, efficient de novo synthesis of glycosphingolipids is dependent on CERT (Hanada et al. 2003; Halter et al. 2007). In contrast, the synthesis of glycosphingolipids from sphingosine is largely independent of CERT (D'Angelo et al. 2007; Giussani et al. 2008), and thus probably relies on vesicular trafficking of ceramide from the ER to the Golgi. The synthesis of most glycosphingolipids begins by the addition of a glucosyl moiety to a ceramide on the cytosolic side of Golgi membranes. Glucosylceramide then needs to be translocated to the lumenal side of the Golgi to be converted to more complex glycosphingolipids. This process requires the involvement of the four-phosphate-adaptor protein 2 (FAPP2). FAPP2 contains a carboxyterminal domain that is homologous to the glycolipid transfer protein (GLTP) domain and binds glucosyl ceramide with high specificity. The amino-terminal region of FAPP2 contains a $\mathrm{PH}$-domain that binds phosphatidyl inositol-4-phosphate and ARF1, which tether the protein to the Golgi (D'Angelo et al. 2007; Halter et al. 2007; Mattjus 2009). Glucosylceramide is converted into lactosylceramide which can then be further glycosylated to more complex glycosphingolipids in the lumenal side of transGolgi membranes. Because of their large and very polar head groups, glycosphingolipids do not readily flip over the membrane and thus remain on the lumenal side. Most of the SM and GSLs synthesized move in transport vesicles from the trans-Golgi network to the plasma membrane where they end up in the extracellular leaflet (van Meer et al. 2008).

\section{Sphingolipid recycling}

Sphingolipids are actively metabolized and recycled via salvage pathways. Some of the metabolic steps can occur at the plasma membrane. For instance, SM can be degraded therein to ceramide by sphingomyelinases, and ceramide can be converted back to SM by the sphingomyelin synthase 2 (SMS2) located at the plasma membrane (Milhas et al. 2010). However, most of the sphingolipid metabolism takes place on intracellular membranes. Some of the endocytosed sphingolipids are transported back to the plasma membrane, whereas others are targeted to lysosomes for degradation. Whether an endocytosed sphingolipid is degraded or recycled back to the plasma membrane is in part dependent on its acyl chain length, with longer chain sphingolipids preferentially targeted for degradation (Koivusalo et al. 2007).

Endocytosed sphingolipids reaching the late endosomal/lysosomal compartments are degraded to simpler sphingolipids in a stepwise manner. This process is accomplished by the concerted action of sphingolipid activator proteins (SAPs) and hydrolytic enzymes. SAPs bind to and lift sphingolipids up from the membrane and then hand over to a hydrolase. However, the acid sphingomyelinase contains an internal saposin-homology domain and can function without the assistance of saposins proper (Linke et al. 2001; Kolter and Sandhoff 2005). As endosomes mature into late endosomes/lysosomes, their lipid composition and structure changes and multivesicular bodies are formed. The vesicles inside these bodies are enriched in an acidic lipid with an unconventional stereochemistry, namely bis-(monoacylglycero)-phosphate (BMP) (Kobayashi et al. 1999; Mobius et al. 2003). SM and the complex sphingolipids in the internal vesicles are oriented so that they face the lumen of the multivesicular bodies/lysosomes. They are thus exposed to the SAPs and acid hydrolases, which allows for their facile degradation (Kolter and Sandhoff 2010).

Eventually, GSLs and SM are degraded to their building blocks, (e.g., monosaccharides), fatty acids and sphingosine. Sphingosine can 
then leave the lysosomes and is either degraded or reused for building new sphingolipids via salvage pathways (Kolter and Sandhoff 2005; Schulze et al. 2009). Sphingosine can reenter the salvage pathway by being acylated in the ER to form ceramide. The reutilization of sphingosine for the synthesis of GSLs is largely independent of CERT, suggesting that this pathway relies on vesicular trafficking of ceramide from the ER to the Golgi apparatus (D'Angelo et al. 2007; Giussani et al. 2008). Sphingosine destined for degradation must first be phosphorylated to sphingosine-1-phosphate, which is then hydrolyzed to phosphoethanolamine and hexadecenal by a sphingosine-1-phosphate lyase in the ER (Ikeda et al. 2004).

\section{BIOSYNTHETIC TRAFFICKING OF STEROLS}

Cholesterol is a major structural lipid in mammalian cell membranes and is enriched in the plasma membrane as well as intracellular membranes that actively communicate with the plasma membrane, such as recycling endosomes and the trans-Golgi network (Ikonen 2008). Cholesterol has a rigid four-ring structure with 17 carbon atoms, to which two methyl groups and an iso-octyl side chain are attached (Fig. 4). All nucleated cells are capable of synthesizing cholesterol by using acetate as the sole carbon source. The rate-limiting enzyme in the pathway, hydroxymethylglutaryl CoA reductase, catalyzes the synthesis of mevalonate. Six enzyme reactions then convert mevalonate to squalene. The mevalonate pathway is also used for the synthesis of other molecules, such as isoprenoids, dolichol, and ubiquinone. The first enzyme in the mevalonate pathway committed to cholesterol synthesis is squalene oxidase. This reaction requires molecular oxygen and the product, lanosterol, is the first cyclic intermediate in the pathway. The steps post lanosterol involve $\sim 20$ enzymatic reactions and there are two alternative pathways depending on whether or not there is a double bond between sterol carbons 24 and 25; the Bloch pathway is followed when the double bond is present, whereas Kandutsch-Russell pathway is followed when it is absent (Fig. 4) (Bloch 1992).
Of the individual sterol biosynthetic steps, the rate-limiting enzyme, HMG CoA reductase (which is the target of the cholesterol lowering statin drugs), has been extensively characterized. HMG CoA reductase is an ER integral membrane protein and is stringently regulated both at the transcriptional and posttranslational levels (see Ye and DeBose-Boyd 2011). Based on enzyme activity measurements, also the later steps of sterol biosynthesis take place in the ER. Sterol synthesis by microsomal enzymes is highly efficient to the extent that organization via multienzyme complex(es) have been suggested (Gaylor and Delwiche 1973). However, several of the cholesterol biosynthetic enzymes are also found in other compartments, such as peroxisomes (presqualene steps [Kovacs et al. 2007]), nucleus (Wu et al. 2004), or nuclear envelope (Zwerger et al. 2010) (sterol 24-reductase and lamin B receptor, respectively), lipid droplets $(\mathrm{NAD}(\mathrm{P}) \mathrm{H}$ steroid dehydrogenase like protein) (Ohashi et al. 2003), and the Golgi complex (Cotman et al. 2004) (lanosterol $14 \alpha$-demethylase). What functions this compartmentalization of the enzymes might serve, is not known.

Although the ER is the main site of cholesterol synthesis, cholesterol concentration in the ER is low. This is because newly synthesized sterols are rapidly transported to other cellular membranes (Fig. 5). The fast transport of the intermediates may also explain the high efficiency of sterol biosynthesis despite the divergent localizations of the enzymes involved. Many of the newly synthesized postlanosterol intermediates can rapidly reach the plasma membrane. They can also be secreted out of cells to physiological (lipoprotein) or pharmacological (e.g., cyclodextrin) acceptors, or return to the ER for conversion into cholesterol (Johnson et al. 1995; Lusa et al. 2003). There is evidence that the efflux of individual precursor sterols from cells to extracellular acceptors varies, with the more polar zymosterol being more avidly effluxed than lathosterol and both exceeding that of newly synthesized cholesterol (Lange et al. 1991; Lusa et al. 2003). Indeed, circulating lathosterol levels can be used as a surrogate marker of cholesterol biosynthetic activity in humans (Gylling et al. 1989). 
T. Blom et al.
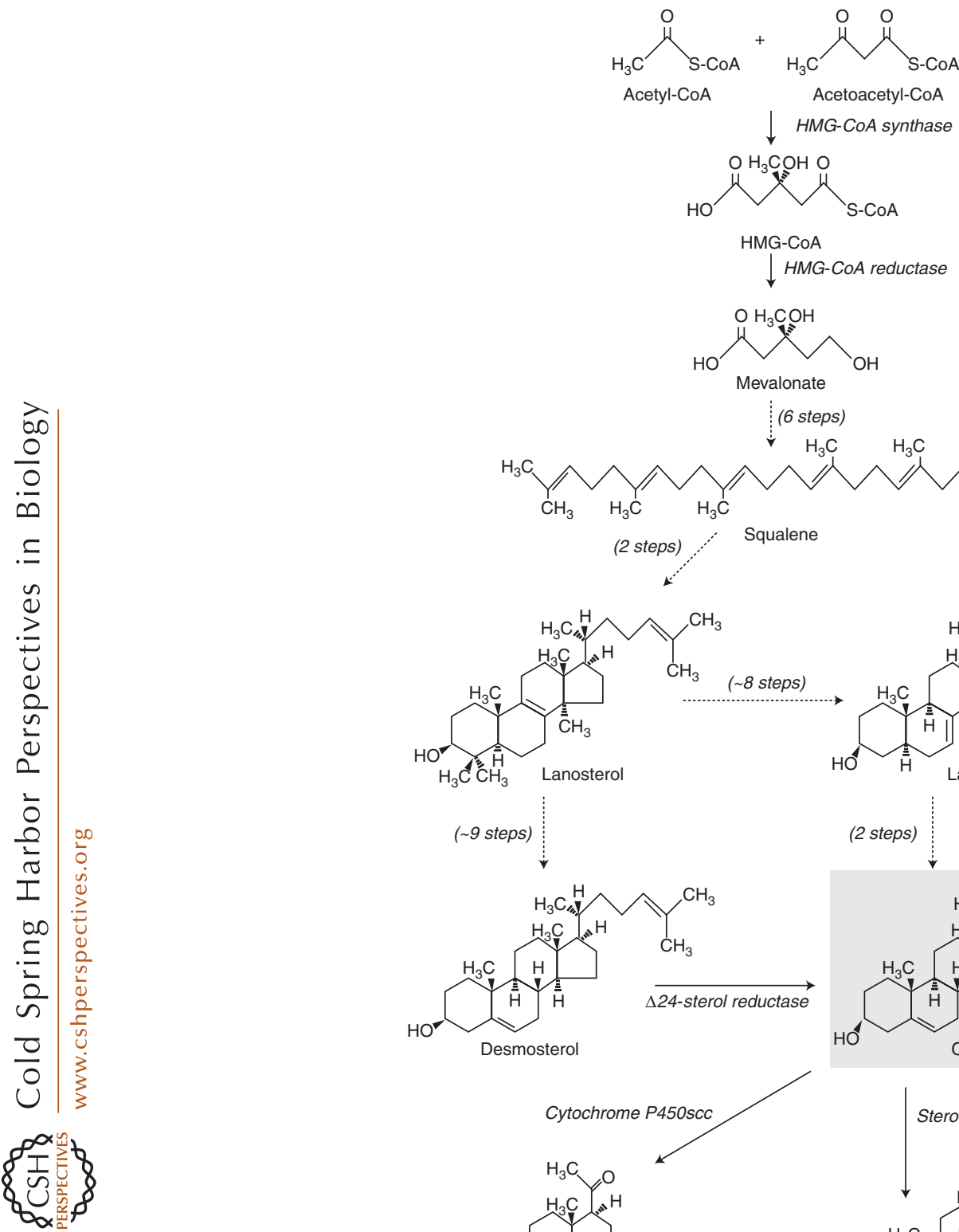

HMG-CoA

$\downarrow$ HMG-COA reductase
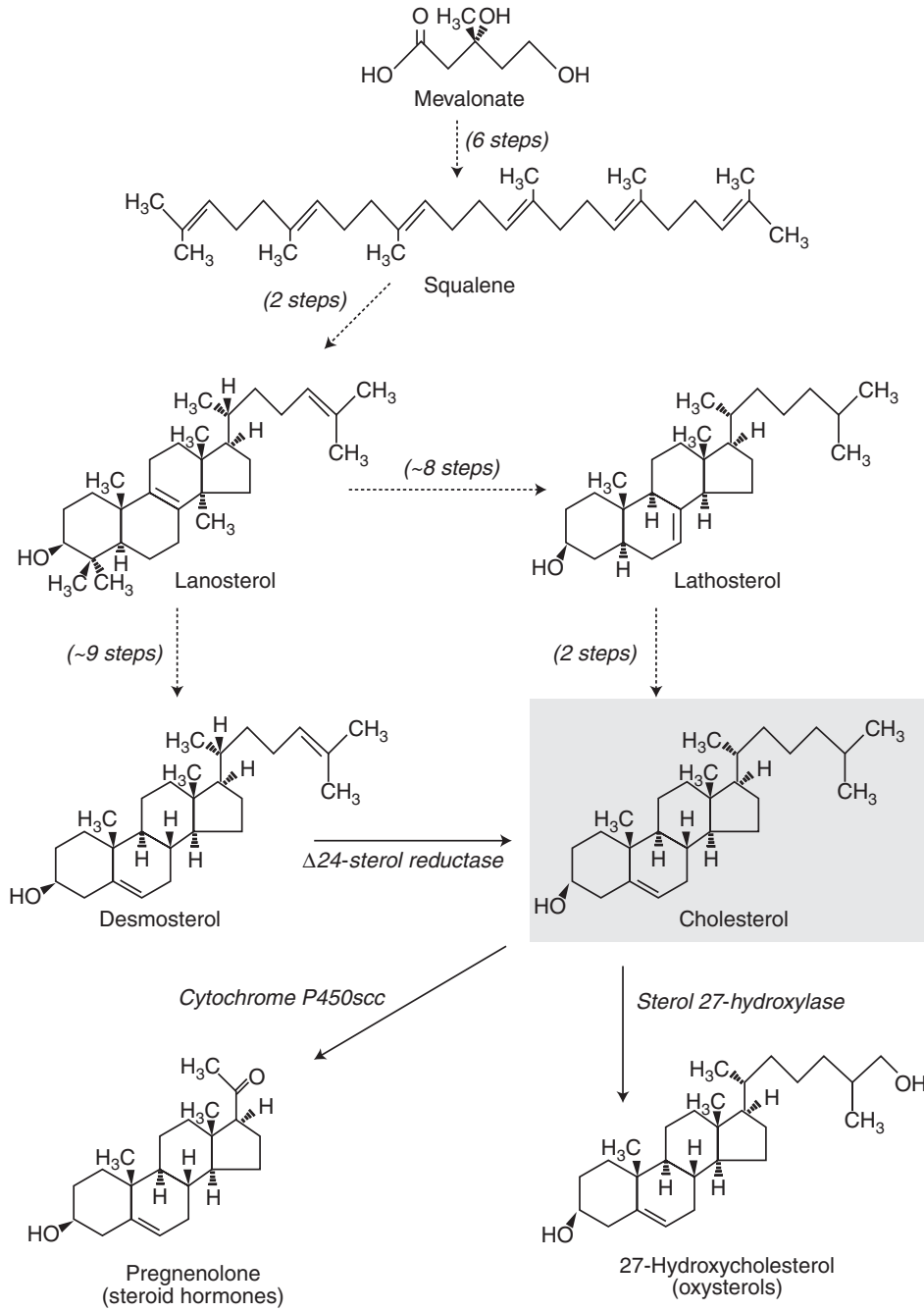

Cholesterol

Figure 4. Overview of the biosynthetic pathways of sterols. The four-ring sterol backbone derives from reductive polymerizations of acetate to generate squalene, which is cyclized to form lanosterol, the first sterol in the pathway. The rate-limiting enzyme of cholesterol biosynthesis is HMG-CoA reductase. The postlanosterol pathway involves roughly 20 steps, with some of the enzymes capable of acting on multiple substrates. If the carbon-24 double bond is reduced early on, the pathway procedes via lathosterol (and 7-dehydrocholesterol, not shown) to cholesterol, whereas reduction of carbon-24 only in the last step results in the generation of desmosterol as the penultimate cholesterol cholesterol precursor. Cholesterol serves as a precursor for other bioactive sterols, such as steroid hormones and oxysterols. 
Lipid Biosynthetic Trafficking

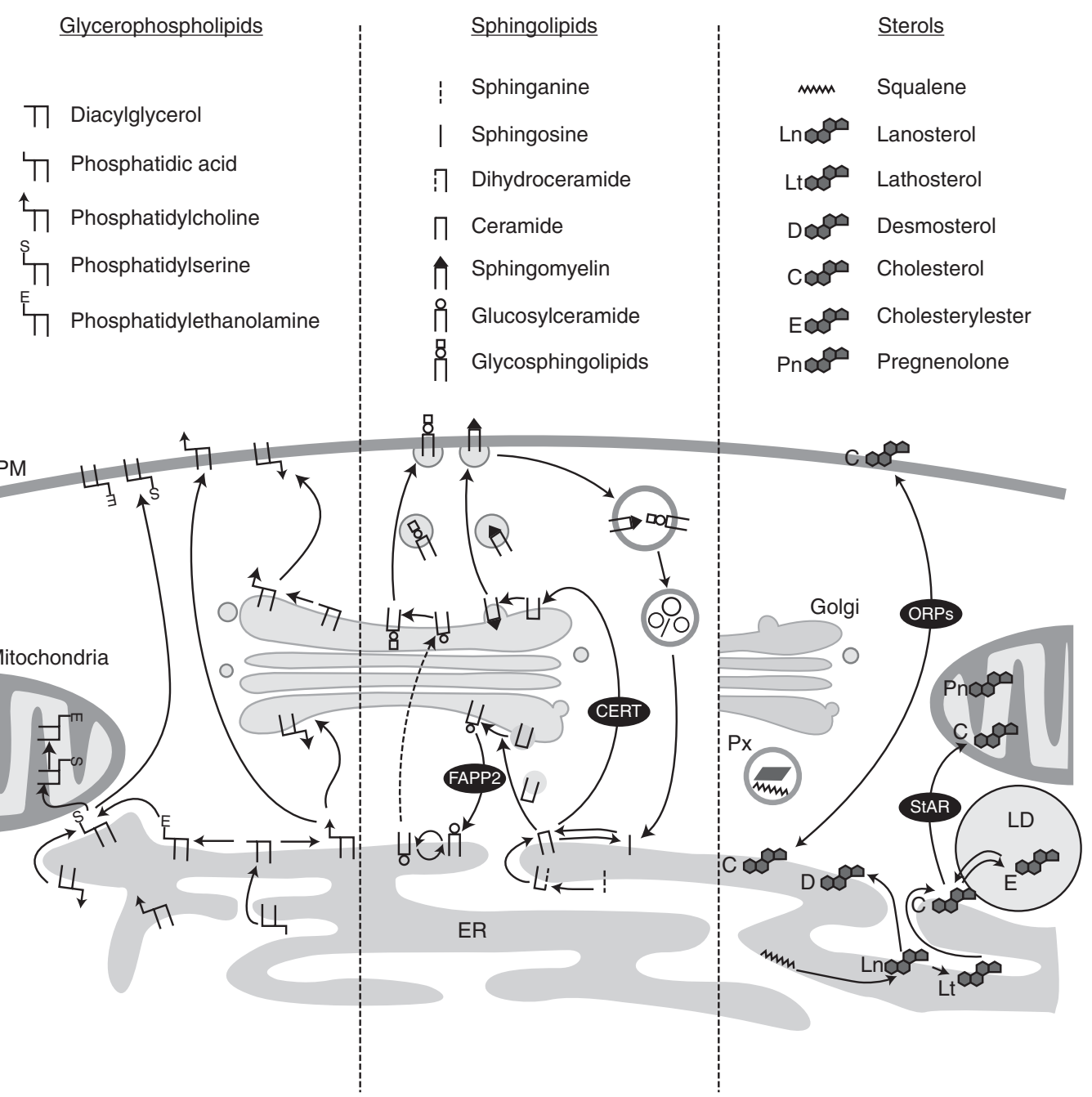

Figure 5. Biosynthetic trafficking of major membrane lipids. (Left) Glycerophospholipids are synthesized in the ER, with phosphatidylserine synthases enriched in mitochondria associated membrane fractions. Glycerophospholipids are transported from the ER both along exocytic membrane transport and by nonvesicular, yet poorly characterized mechanisms. (Middle) De novo sphingolipid synthesis is initiated in the ER. The ER to Golgi transport of ceramide for the assembly of more complex sphingolipids is mediated by CERT, and to a lesser extent by membrane transport. The post-Golgi transport of complex sphingolipids is dependent on membrane transport. Sphingosine that stems from lysosomally degraded complex sphingolipids can be acylated to form ceramide in the ER and recycled to sphingomyelin and glycosphingolipids. (Right) Cholesterol biosynthetic enzymes reside in the ER, with some presqualene enzymes also localized in peroxisomes (Px). Sterols are transported to the plasma membrane (PM) largely via Golgi bypass route(s) and the ORP proteins play a role in this process, as well as in the reverse transport from the plasma membrane to the ER. Sterols imported into mitochondria by StAR can be used for steroid hormone synthesis. Excess cholesterol can be esterified in the ER by acyl-CoA cholesterol acyltransferase and stored in lipid droplets (LD). Arrows indicate the direction of lipid transport. Please note that arrows do not necessarily reflect the transport distance as membranes move constantly and lipid transfer may be facilitated by close apposition of membranes. Carrier proteins are indicated by black circles. 
T. Blom et al.

The techniques available to study the mechanisms of biosynthetic sterol trafficking from the ER to the more sterol-enriched membranes are indirect. Typically, cells are labeled with the radioactive precursors acetate or mevalonate, chased, and the incorporation of the radiolabel into cholesterol is measured, after subcellular fractionation, lipid extraction, and chromatographic separation of the radiolabeled lipophilic compounds. A simpler method for analyzing the plasma membrane arrival of sterols is rapid extraction of sterols to the efficient extracellular acceptor, methyl $\beta$ cyclodextrin. This should be performed at reduced temperature (Heino et al. 2000), because at $37^{\circ} \mathrm{C}$ cyclodextrin is endocytosed and no longer assesses only the plasma membrane sterol pool (Rosenbaum et al. 2010).

Most of the newly synthesized cholesterol can reach the plasma membrane by route(s) that bypass the Golgi complex as assessed by pharmacological disassembly of the Golgi complex by using Brefeldin A treatment (Urbani and Simoni 1990; Heino et al. 2000) or by genetic perturbation of ER-Golgi membrane transport in yeast (Baumann et al. 2005). Interestingly, in yeast steroids and sterols can be acetylated by a sterol acetyltransferase bound to the ER membrane. This acetylation controls the export of steroids and sterols from cells via the secretory pathway, and acts as a lipid detoxification mechanism (Tiwari et al. 2007). Acetylation renders the lipid more hydrophobic, conferring higher affinity for membranes, and apparently therefore preferential delivery via membrane transport. Instead, mammals use a different strategy for sterol excretion: cholesterol is rendered increasingly hydrophilic via oxidation to generate oxysterols (Fig. 4) (followed by further oxidation to bile acids in the liver) (Russell 2003) to increase water solubility and excretion into the aqueous extracellular milieu.

There is increasing evidence for the role of soluble sterol carrier proteins in facilitating sterol trafficking between cellular membranes. Particularly two sterol-binding protein families, the START (steroidogenic acute regulatory protein related lipid transfer) and ORP (oxysterolbinding protein related protein) families are important in this process (Lavigne et al. 2010; Ridgway 2010). These proteins are encoded by 27 genes comprising almost $0.1 \%$ of the entire human genome (Ngo et al. 2010). The START and ORP proteins have verified sterol-binding domains (several of which have been crystallized) and adjacent regulatory and membranetargeting motifs.

The steroidogenic acute regulatory protein (StAR) is the prototype of the START family proteins. StAR regulates the rate-limiting step in steroid hormone biosynthesis, that is, the delivery of cholesterol into the mitochondrial inner membrane (Manna et al. 2009). This membrane harbors the $\mathrm{P} 450$ side chain cleavage enzyme that catalyzes pregnenolone production from cholesterol. StAR is a labile phosphoprotein whose synthesis correlates tightly with steroid synthesis. Its amino-terminal mitochondrial leader sequence is cleaved during or after translocation into mitochondria, leaving intact the START domain that is responsible for inducing cholesterol transfer. However, the role of mitochondrial targeting and processing of StAR on steroidogenesisis is controversial, as the START domain can function at the outer mitochondrial membrane (Arakane et al. 1996), and internalization of StAR into mitochondria does not appear necessary for the sterol transfer (Bose et al. 2002).

In yeast, ORP homologs (Osh proteins) have been implicated in ER-plasma membrane sterol delivery. Moreover, recent data implicate Osh and ORP proteins in bidirectional delivery of sterols between the plasma membrane and the ER (Raychaudhuri et al. 2006; Jansen et al. 2011). Several of the ORP proteins carry a FFAT (phenylalanine in an acidic tract) motif that interacts with the ER protein VAMP associated membrane protein (VAP) (Loewen et al. 2003). This may display a regulatory function in sterol transfer analogously to CERT, in which this motif regulates ER interaction and ceramide transfer activity (Kawano et al. 2006). The plextrin homology $(\mathrm{PH})$ domains present in several ORPs may provide additional binding specifities between donor and acceptor membranes. PIP interactions may also take place in the absence of a PH domain, as in Osh4, where 
a membrane-binding surface of the protein can generate a phosphoinositide binding site (Schulz et al. 2009). In mammalian cells, ORP2 was shown to enhance biosynthetic sterol trafficking from the ER to the plasma membrane (Hynynen et al. 2005). It can also facilitate the delivery of sterols in the reverse direction, from the plasma membrane to the ER and lipid droplets (Jansen et al. 2011).

\section{CONCLUDING REMARKS AND FUTURE PROSPECTS}

The enzymes involved in the biosynthesis of glycerophospholipids, sphingolipids, and sterols have been characterized, and there is ample information on the regulation of the rate-limiting enzymes of the pathways. Instead, insight into the mechanisms of delivery of newly synthesized lipids to their target membranes in cells is less comprehensive.

Although the basic biophysical principles of lipid mobility have been extensively studied in model membranes, the unequivocal identification of physiologically relevant mediators of lipid transfer has not been easy. A major challenge is the redundancy of lipid trafficking systems in cells. This calls for manipulations that can target an entire protein family, for instance by pharmacologic compounds, or by genetic strategies in multicellular organisms, as has been pioneered in yeast. Moreover, analytical tools need to be further developed. Mass spectrometry based lipidomics has only recently opened the possibility to obtain comprehensive and precise structural information on individual lipid molecules. This technology should be extended and complemented with improved imaging systems to visualizing lipids and lipid-protein interactions in cells and tissues, to obtain improved spatial and temporal information on lipid delivery.

Finally, it is important to acknowledge that despite the redundancy in lipid biosynthetic trafficking systems, not all delivery systems are backed up in all cells. This is exemplified by human diseases because of defects in this process that manifest as complex tissue level malfunction. For instance, loss of function mutations in the mitochondrial cholesterol transporter StAR cause a severe impairment in the synthesis of all adrenal and gonadal steroid hormones, resulting in lipoid congenital adrenal hyperplasia (Lin et al. 1995), whereas mutations in the keratinocyte lipid transporter ABCA12 cause a skin disorder, harlequin ichtyosis, that results from the loss of long-chain ceramide esters in the skin and disruption of the epidermal permeability barrier (Zuo et al. 2008). Such examples with Mendelian inheritance patterns represent the severe end of the spectrum, the tip of the iceberg, in lipid synthesis and delivery problems in human disease. With improved analytical technologies, the number and variety of such disturbances is bound to increase.

\section{ACKNOWLEDGMENTS}

This study was supported by the Academy of Finland grant nos. 123261 (T.B.), 131429, and 218066 (E.I.).

\section{REFERENCES}

Achleitner G, Gaigg B, Krasser A, Kainersdorfer E, Kohlwein SD, Perktold A, Zellnig G, Daum G. 1999. Association between the endoplasmic reticulum and mitochondria of yeast facilitates interorganelle transport of phospholipids through membrane contact. Eur J Biochem 264: 545-553.

Achleitner G, Zweytick D, Trotter PJ, Voelker DR, Daum G. 1995. Synthesis and intracellular transport of aminoglycerophospholipids in permeabilized cells of the yeast, Saccharomyces cerevisiae. J Biol Chem 270: 29836-29842.

Arakane F, Sugawara T, Nishino H, Liu Z, Holt JA, Pain D, Stocco DM, Miller WL, Strauss JF III. 1996. Steroidogenic acute regulatory protein (StAR) retains activity in the absence of its mitochondrial import sequence: Implications for the mechanism of StAR action. Proc Natl Acad Sci 93: 13731-13736.

Baumann NA, Sullivan DP, Ohvo-Rekila H, Simonot C, Potteka A, Klaassen Z, Beh CT, Menon AK. 2005. Transport of newly synthesized sterol to the sterol-enriched plasma membrane occurs via nonvesicular equilibration. Biochemistry 44: 5816-5826.

Ben-David O, Futerman AH. 2010 The role of the ceramide acyl chain length in neurodegeneration: Involvement of ceramide synthases. Neuromolecular Med 12: 341-350.

Bloch K. 1992. Sterol molecule: Structure, biosynthesis, and function. Steroids 57: 378-383.

Bose HS, Lingappa VR, Miller WL. 2002. Rapid regulation of steroidogenesis by mitochondrial protein import. Nature 417: 87-91. 
T. Blom et al.

Buton X, Morrot G, Fellmann P, Seigneuret M. 1996. Ultrafast glycerophospholipid-selective transbilayer motion mediated by a protein in the endoplasmic reticulum membrane. J Biol Chem 271: 6651-6657.

Coskun U, Simons K. 2010. Membrane rafting: From apical sorting to phase segregation. FEBS Lett 584: 1685-1693.

Cotman M, Jezek D, Fon Tacer K, Frangez R, Rozman D. 2004. A functional cytochrome P450 lanosterol 14 $\alpha$-demethylase CYP51 enzyme in the acrosome: Transport through the Golgi and synthesis of meiosis-activating sterols. Endocrinology 145: 1419-1426.

D’Angelo G, Vicinanza M, DeMatteis MA. 2008. Lipidtransfer proteins in biosynthetic pathways. Curr Opin Cell Biol 20: 360-370.

D’Angelo G, Polishchuk E, Di Tullio G, Santoro M, Di Campli A, Godi A, West G, Bielawski J, Chuang CC, van der Spoel AC, et al. 2007. Glycosphingolipid synthesis requires FAPP2 transfer of glucosylceramide. Nature 449: $62-67$.

Daleke DL. 2007. Phospholipid flippases. J Biol Chem 282: 821-825.

Ewers H, Romer W, Smith AE, Bacia K, Dmitrieff S, Chai W, Mancini R, Kartenbeck J, Chambon V, Berland L, et al. 2010. GM1 structure determines SV40-induced membrane invagination and infection. Nat Cell Biol 12: $11-12$.

Futerman AH, Riezman H. 2005. The ins and outs of sphingolipid synthesis. Trends Cell Biol 15: 312-318.

Gaylor JL, Delwiche CV. 1973. Investigation of the multienzymic system of microsomal cholesterol biosynthesis. Ann N Y Acad Sci 212: 122-138.

Giussani P, Colleoni T, Brioschi L, Bassi R, Hanada K, Tettamanti G, Riboni L, Viani P. 2008. Ceramide traffic in C6 glioma cells: Evidence for CERT-dependent and independent transport from ER to the Golgi apparatus. Biochim Biophys Acta 1781: 40-51.

Gylling H, Kuusi T, Vanhanen H, Miettinen TA. 1989. Apolipoprotein $\mathrm{E}$ phenotype and cholesterol metabolism in familial hypercholesterolemia. Atherosclerosis 80: 27-32.

Halter D, Neumann S, van Dijk SM, Wolthoorn J, de Maziere AM, Vieira OV, Mattjus P, Klumperman J, van Meer G, Sprong H. 2007. Pre- and post-Golgi translocation of glucosylceramide in glycosphingolipid synthesis. J Cell Biol 179: 101-115.

Hanada K, Kumagai K, Tomishige N, Yamaji T. 2009. CERTmediated trafficking of ceramide. Biochim Biophys Acto 1791: 684-691.

Hanada K, Kumagai K, Yasuda S, Miura Y, Kawano M, Fukasawa M, Nishijima M. 2003. Molecular machinery for non-vesicular trafficking of ceramide. Nature 426: 803-809.

Hannun YA, Obeid LM. 2008. Principles of bioactive lipid signalling: Lessons from sphingolipids. Nat Rev Mol Cell Biol 9: 139-150.

Heikinheimo L, Somerharju P. 1998. Preferential decarboxylation of hydrophilic phosphatidylserine species in cultured cells. Implications on the mechanism of transport to mitochondria and cellular aminophospholipid species compositions. J Biol Chem 273: 3327-3335.

Heikinheimo L, Somerharju P. 2002. Translocation of phosphatidylthreonine and -serine to mitochondria diminishes exponentially with increasing molecular hydrophobicity. Traffic 3: 367-377.

Heino S, Lusa S, Somerharju P, Ehnholm C, Olkkonen VM, Ikonen E. 2000. Dissecting the role of the golgi complex and lipid rafts in biosynthetic transport of cholesterol to the cell surface. Proc Natl Acad Sci 97: 8375-8380.

Henneberry AL, McMaster CR. 1999. Cloning and expression of a human choline/ethanolaminephosphotransferase: Synthesis of phosphatidylcholine and phosphatidylethanolamine. Biochem J 339: 291-298.

Henneberry AL, Wistow G, McMaster CR. 2000. Cloning, genomic organization, and characterization of a human cholinephosphotransferase. J Biol Chem 275: $29808-$ 29815.

Henneberry AL, Wright MM, McMaster CR. 2002. The major sites of cellular phospholipid synthesis and molecular determinants of fatty acid and lipid head group specificity. Mol Biol Cell 13: 3148-3161.

Holthuis JC, Levine TP. 2005. Lipid traffic: Floppy drives and a superhighway. Nat Rev Mol Cell Biol 6: 209-220.

Horibata Y, Hirabayashi Y. 2007. Identification and characterization of human ethanolaminephosphotransferase 1. J Lipid Res 48: 503-508.

Horibata Y, Sugimoto H. 2010 StarD7 mediates the intracellular trafficking of phosphatidylcholine to mitochondria. J Biol Chem 285: 7358-7365.

Hynynen R, Laitinen S, Kakela R, Tanhuanpaa K, Lusa S, Ehnholm C, Somerharju P, Ikonen E, Olkkonen VM. 2005. Overexpression of OSBP-related protein 2 (ORP2) induces changes in cellular cholesterol metabolism and enhances endocytosis. Biochem J 390: 273-283.

Ikeda M, Kihara A, Igarashi Y. 2004. Sphingosine-1phosphate lyase SPL is an endoplasmic reticulumresident, integral membrane protein with the pyridoxal $5^{\prime}$-phosphate binding domain exposed to the cytosol. Biochem Biophys Res Commun 325: 338-343.

Ikonen E. 2008. Cellular cholesterol trafficking and compartmentalization. Nat Rev Mol Cell Biol 9: 125-138.

Jansen M, Ohsaki Y, Rega LR, Bittman R, Olkkonen VM, Ikonen E. 2010. Role of ORPs in sterol transport from plasma membrane to ER and lipid droplets in mammalian cells. Traffic 12: $218-231$.

Jasinska R, Zborowski J, Somerharju P. 1993. Intramitochondrial distribution and transport of phosphatidylserine and its decarboxylation product, phosphatidylethanolamine. Application of pyrene-labeled species. Biochim Biophys Acta 1152: 161-170.

Johnson WJ, Fischer RT, Phillips MC, Rothblat GH. 1995. Efflux of newly synthesized cholesterol and biosynthetic sterol intermediates from cells. Dependence on acceptor type and on enrichment of cells with cholesterol. J Biol Chem 270: 25037-25046.

Kang HW, Wei J, Cohen DE. 2010 PC-TP/StARD2: Of membranes and metabolism. Trends Endocrinol Metab 21: $449-456$.

Kanno K, Wu MK, Scapa EF, Roderick SL, Cohen DE. 2007. Structure and function of phosphatidylcholine transfer protein (PC-TP)/StarD2. Biochim Biophys Acta 1771: $654-662$. 
Kaplan MR, Simoni RD. 1985. Intracellular transport of phosphatidylcholine to the plasma membrane. J Cell Biol 101: 441-445.

Kawano M, Kumagai K, Nishijima M, Hanada K. 2006. Efficient trafficking of ceramide from the endoplasmic reticulum to the Golgi apparatus requires a VAMP-associated protein-interacting FFAT motif of CERT. J Biol Chem 281: 30279-30288.

Kobayashi T, Beuchat MH, Lindsay M, Frias S, Palmiter RD, Sakuraba H, Parton RG, Gruenberg J. 1999. Late endosomal membranes rich in lysobisphosphatidic acid regulate cholesterol transport. Nat Cell Biol 1: 113-118.

Koivusalo M, Jansen M, Somerharju P, Ikonen E. 2007. Endocytic trafficking of sphingomyelin depends on its acyl chain length. Mol Biol Cell 18: 5113-5123.

Kol MA, de Kroon AI, Killian JA, de Kruijff B. 2004. Transbilayer movement of phospholipids in biogenic membranes. Biochemistry 43: 2673-2681.

Kolter T, Sandhoff K. 2005. Principles of lysosomal membrane digestion: Stimulation of sphingolipid degradation by sphingolipid activator proteins and anionic lysosomal lipids. Annu Rev Cell Dev Biol 21: 81-103.

Kolter T, Sandhoff K. 2010 Lysosomal degradation of membrane lipids. FEBS Lett 584: 1700-1712.

Kovacs WJ, Tape KN, Shackelford JE, Duan X, Kasumov T, Kelleher JK, Brunengraber H, Krisans SK. 2007. Localization of the pre-squalene segment of the isoprenoid biosynthetic pathway in mammalian peroxisomes. Histochem Cell Biol 127: 273-290.

Kudo N, Kumagai K, Matsubara R, Kobayashi S, Hanada K, Wakatsuki S, Kato R. 2010. Crystal structures of the CERT START domain with inhibitors provide insights into the mechanism of ceramide transfer. J Mol Biol 396: $245-251$.

Kudo N, Kumagai K, Tomishige N, Yamaji T, Wakatsuki S, Nishijima M, Hanada K, Kato R. 2008. Structural basis for specific lipid recognition by CERT responsible for nonvesicular trafficking of ceramide. Proc Natl Acad Sci 105: 488-493.

Kumagai K, Yasuda S, Okemoto K, Nishijima M, Kobayashi S, Hanada K. 2005. CERT mediates intermembrane transfer of various molecular species of ceramides. $J$ Biol Chem 280: 6488-6495.

Lahiri S, Futerman AH. 2007. The metabolism and function of sphingolipids and glycosphingolipids. Cell Mol Life Sci 64: $2270-2284$.

Lange Y, Echevarria F, Steck TL. 1991. Movement of zymosterol, a precursor of cholesterol, among three membranes in human fibroblasts. J Biol Chem 266: 21439-21443.

Lavigne P, Najmanivich R, Lehoux JG. 2010. Mammalian StAR-related lipid transfer (START) domains with specificity for cholesterol: Structural conservation and mechanism of reversible binding. Subcell Biochem 51: 425-437.

Lev S. 2010. Non-vesicular lipid transport by lipid transfer proteins and beyond. Nat Rev Mol Cell Biol 11: 739-750.

Leventis PA, Grinstein S. 2010. The distribution and function of phosphatidylserine in cellular membranes. Annu Rev Biophys 39: 407-427.

Lin D, Sugawara T, Strauss JF III, Clark BJ, Stocco DM, Saenger P, Rogol A, Miller WL. 1995. Role of steroidogenic acute regulatory protein in adrenal and gonadal steroidogenesis. Science 267: 1828-1831.

Linke T, Wilkening G, Lansmann S, Moczall H, Bartelsen O, Weisgerber J, Sandhoff K. 2001. Stimulation of acid sphingomyelinase activity by lysosomal lipids and sphingolipid activator proteins. Biol Chem 382: 283-290.

Loewen CJ, Roy A, Levine TP. 2003. A conserved ER targeting motif in three families of lipid binding proteins and in Opilp binds VAP. Embo J 22: 2025-2035.

Lusa S, Heino S, Ikonen E. 2003. Differential mobilization of newly synthesized cholesterol and biosynthetic sterol precursors from cells. J Biol Chem 278: 19844-19851.

Manna PR, Dyson MT, Stocco DM. 2009. Regulation of the steroidogenic acute regulatory protein gene expression: Present and future perspectives. Mol Hum Reprod 15: 321-333.

Mattjus P. 2009. Glycolipid transfer proteins and membrane interaction. Biochim Biophys Acta 1788: 267-272.

Milhas D, Clarke CJ, Hannun YA. 2010. Sphingomyelin metabolism at the plasma membrane: Implications for bioactive sphingolipids. FEBS Lett 584: 1887-1894.

Mobius W, van Donselaar E, Ohno-Iwashita Y, Shimada Y, Heijnen HF, Slot JW, Geuze HJ. 2003. Recycling compartments and the internal vesicles of multivesicular bodies harbor most of the cholesterol found in the endocytic pathway. Traffic 4: 222-231.

Ngo MH, Colbourne TR, Ridgway ND. 2010. Functional implications of sterol transport by the oxysterol-binding protein gene family. Biochem J 429: 13-24.

Nishizuka Y. 1992. Intracellular signaling by hydrolysis of phospholipids and activation of protein kinase C. Science 258: 607-614.

Ohashi M, Mizushima N, Kabeya Y, Yoshimori T. 2003. Localization of mammalian NAD(P)H steroid dehydrogenase-like protein on lipid droplets. J Biol Chem 278: 36819-36829.

Olayioye MA, Vehring S, Muller P, Herrmann A, Schiller J, Thiele C, Lindeman GJ, Visvader JE, Pomorski T. 2005. StarD10, a START domain protein overexpressed in breast cancer, functions as a phospholipid transfer protein. J Biol Chem 280: 27436-27442.

Raff MC, Mirsky R, Fields KL, Lisak RP, Dorfman SH, Silberberg DH, Gregson NA, Leibowitz S, Kennedy MC. 1978. Galactocerebroside is a specific cell-surface antigenic marker for oligodendrocytes in culture. Nature 274: 813-816.

Raychaudhuri S, Im YJ, Hurley JH, Prinz WA. 2006. Nonvesicular sterol movement from plasma membrane to ER requires oxysterol-binding protein-related proteins and phosphoinositides. J Cell Biol 173: 107-119.

Ridgway ND. 2010. Oxysterol-binding proteins. Subcell Biochem 51: 159-182.

Riekhof WR, Voelker DR. 2009. The yeast plasma membrane P4-ATPases are major transporters for lysophospholipids. Biochim Biophys Acta 1791: 620-627.

Rosenbaum AI, Zhang G, Warren JD, Maxfield FR. 2010. Endocytosis of $\beta$-cyclodextrins is responsible for cholesterol reduction in Niemann-Pick type C mutant cells. Proc Natl Acad Sci 107: 5477-5482.

Russell DW. 2003. The enzymes, regulation, and genetics of bile acid synthesis. Annu Rev Biochem 72: 137-174. 
T. Blom et al.

Sabourdy F, Kedjouar B, Sorli SC, Colie S, Milhas D, Salma Y, Levade T. 2008. Functions of sphingolipid metabolism in mammals-lessons from genetic defects. Biochim Biophys Acta 1781: 145-183.

Schulze H, Kolter T, Sandhoff K. 2009. Principles of lysosomal membrane degradation: Cellular topology and biochemistry of lysosomal lipid degradation. Biochim Biophys Acta 1793: 674-683.

Schulz TA, Choi MG, Raychaudhuri S, Mears JA, Ghirlando R, Hinshaw JE, Prinz WA. 2009. Lipid-regulated sterol transfer between closely apposed membranes by oxysterol-binding protein homologues. J Cell Biol 187: 889-903.

Shiao YJ, Lupo G, Vance JE. 1995. Evidence that phosphatidylserine is imported into mitochondria via a mitochondria-associated membrane and that the majority of mitochondrial phosphatidylethanolamine is derived from decarboxylation of phosphatidylserine. J Biol Chem 270: 11190-11198.

Simons K, Ikonen E. 1997. Functional rafts in cell membranes. Nature 387: 569-572.

Smriti, Nemergut EC, Daleke DL. 2007. ATP-dependent transport of phosphatidylserine analogues in human erythrocytes. Biochemistry 46: 2249-2259.

Sprong H, Degroote S, Nilsson T, Kawakita M, Ishida N van der Sluijs P, van Meer G. 2003. Association of the Golgi UDP-galactose transporter with UDPgalactose:ceramide galactosyltransferase allows UDPgalactose import in the endoplasmic reticulum. Mol Biol Cell 14: 3482-3493.

Steenbergen R, Nanowski TS, Beigneux A, Kulinski A, Young SG, Vance JE. 2005. Disruption of the phosphatidylserine decarboxylase gene in mice causes embryonic lethality and mitochondrial defects. J Biol Chem 280: 40032-40040.

Stoffel W, Bosio A. 1997. Myelin glycolipids and their functions. Curr Opin Neurobiol 7: 654-661.

Stone SJ, Vance JE. 2000. Phosphatidylserine synthase-1 and -2 are localized to mitochondria-associated membranes. J Biol Chem 275: 34534-34540.

Tafesse FG, Ternes P, Holthuis JC. 2006. The multigenic sphingomyelin synthase family. J Biol Chem 281: 29421-29425.

Tiwari R, Koffel R, Schneiter R. 2007. An acetylation/deacetylation cycle controls the export of sterols and steroids from S. cerevisiae. Embo J 26: 5109-5119.

Trajkovic K, Hsu C, Chiantia S, Rajendran L, Wenzel D, Wieland F, Schwille P, Brugger B, Simons M. 2008. Ceramide triggers budding of exosome vesicles into multivesicular endosomes. Science 319: 1244-1247.
Urbani L, Simoni RD. 1990. Cholesterol and vesicular stomatitis virus $G$ protein take separate routes from the endoplasmic reticulum to the plasma membrane. J Biol Chem 265: 1919-1923.

van Meer G, Voelker DR, Feigenson GW. 2008. Membrane lipids: Where they are and how they behave. Nat Rev Mol Cell Biol 9: 112-124.

Vance JE. 2008. Phosphatidylserine and phosphatidylethanolamine in mammalian cells: Two metabolically related aminophospholipids. J Lipid Res 49: 1377-1387.

Voelker DR. 1985. Disruption of phosphatidylserine translocation to the mitochondria in baby hamster kidney cells. J Biol Chem 260: 14671-14676.

Voelker DR. 2009. Genetic and biochemical analysis of nonvesicular lipid traffic. Annu Rev Biochem 78: 827-856.

Weisz OA, Rodriguez-Boulan E. 2009. Apical trafficking in epithelial cells: Signals, clusters and motors. J Cell Sci 122: $4253-4266$.

Wirtz KW. 2006. Phospholipid transfer proteins in perspective. FEBS Lett 580: 5436-5441.

Wirtz KW, Zilversmit DB. 1969. Participation of soluble liver proteins in the exchange of membrane phospholipids. Biochim Biophys Acta 193: 105-116.

Wirtz KW, Schouten A, Gros P. 2006. Phosphatidylinositol transfer proteins: From closed for transport to open for exchange. Advan Enzyme Regul 46: 301-311.

Wu C, Miloslavskaya I, Demontis S, Maestro R, Galaktionov K. 2004. Regulation of cellular response to oncogenic and oxidative stress by Seladin-1. Nature 432: 640-645.

Yamaji T, Kumagai K, Tomishige N, Hanada K. 2008. Two sphingolipid transfer proteins, CERT and FAPP2: Their roles in sphingolipid metabolism. IUBMB Life 60: 511-518.

Ye J, DeBose-Boyd A. 2011. Regulation of cholesterol and fatty acid synthesis. Cold Spring Harb Perspect Biol doi.10.1101/cshperspect.a004754.

Zborowski J, Dygas A, Wojtczak L. 1983. Phosphatidylserine decarboxylase is located on the external side of the inner mitochondrial membrane. FEBS Lett 157: 179-182.

Zuo Y, Zhuang DZ, Han R, Isaac G, Tobin JJ, McKee M, Welti R, Brissette JL, Fitzgerald ML, Freeman MW. 2008. ABCA12 maintains the epidermal lipid permeability barrier by facilitating formation of ceramide linoleic esters. J Biol Chem 283: 36624-36635.

Zwerger M, Kolb T, Richter K, Karakesisoglou I, Herrmann H. 2010. Induction of a massive endoplasmic reticulum and perinuclear space expansion by expression of lamin $\mathrm{B}$ receptor mutants and the related sterol reductases TM7SF2 and DHCR7. Mol Biol Cell 21: 354-368. 


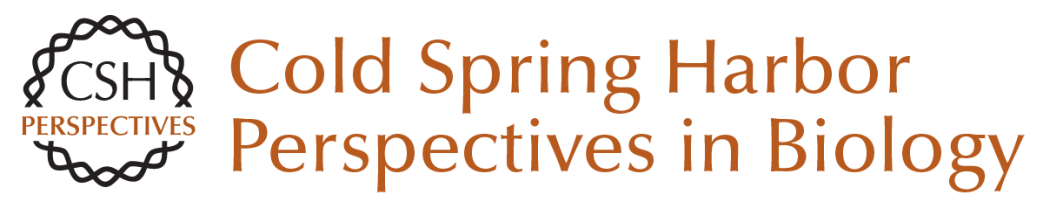

\section{Synthesis and Biosynthetic Trafficking of Membrane Lipids}

Tomas Blom, Pentti Somerharju and Elina Ikonen

Cold Spring Harb Perspect Biol 2011; doi: 10.1101/cshperspect.a004713 originally published online April 11,2011

\section{Subject Collection The Biology of Lipids}

Role of Lipids in Virus Replication Maier Lorizate and Hans-Georg Kräusslich

Model Answers to Lipid Membrane Questions Ole G. Mouritsen

\section{Glycosphingolipid Functions} Clifford A. Lingwood

Regulation of Cholesterol and Fatty Acid Synthesis

Jin Ye and Russell A. DeBose-Boyd

\section{Lipid-Mediated Endocytosis}

Helge Ewers and Ari Helenius

\section{Fluorescence Techniques to Study Lipid}

Dynamics

Erdinc Sezgin and Petra Schwille

Lysosomal Lipid Storage Diseases

Heike Schulze and Konrad Sandhoff

\section{Distribution and Functions of Sterols and} Sphingolipids

J. Thomas Hannich, Kyohei Umebayashi and Howard Riezman
Membrane Organization and Lipid Rafts Kai Simons and Julio L. Sampaio

Shotgun Lipidomics on High Resolution Mass

Spectrometers

Dominik Schwudke, Kai Schuhmann, Ronny

Herzog, et al.

Glycosphingolipid Functions Clifford A. Lingwood

Phosphoinositides in Cell Architecture Annette Shewan, Dennis J. Eastburn and Keith Mostov

Synthesis and Biosynthetic Trafficking of Membrane Lipids

Tomas Blom, Pentti Somerharju and Elina Ikonen

Lipid Polymorphisms and Membrane Shape Vadim A. Frolov, Anna V. Shnyrova and Joshua Zimmerberg

Specificity of Intramembrane Protein-Lipid Interactions

Francesc-Xabier Contreras, Andreas Max Ernst, Felix Wieland, et al.

Dynamic Transbilayer Lipid Asymmetry Gerrit van Meer

For additional articles in this collection, see http://cshperspectives.cshlp.org/cgi/collection/

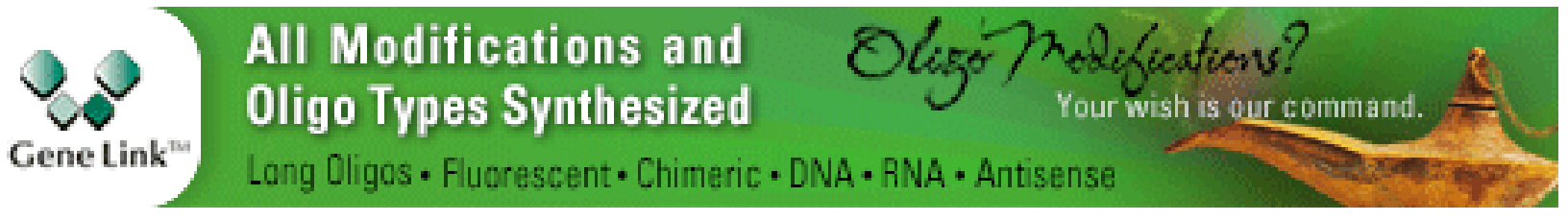

Copyright @ 2011 Cold Spring Harbor Laboratory Press; all rights reserved 